\title{
Paratesticular Leiomyosarcoma Treated by Enucleation
}

\author{
Roberto I. Lopes, Katia R. Leite, Roberto N. Lopes \\ Syrian Lebanese Hospital, Sao Paulo, Brazil
}

\begin{abstract}
Spermatic cord leiomyosarcomas are rare tumors and standard treatment consists of radical orchiectomy and high cord ligation. We report a case of a paratesticular leiomyosarcoma successfully treated by enucleation.

A 22-year-old man presented with a 6-months history of inguinal pain. Physical examination revealed a right paratesticular nodule about $0.5 \mathrm{~cm}$ in diameter. Inguinal exploration and nodule biopsy were performed. It was thought to be a benign epididymal nodule on a quick section and the tumor was enucleated and sent for paraffin section. Histology and immunohistochemistry were compatible with leiomyosarcoma. The patient was advised to undergo radical orchiectomy with high cord ligation. However, he refused surgery. An alternative approach with clinical, biochemical and radiological follow-up was adopted. The patient has been followed up for thirteen years and shows no evidence of disease.
\end{abstract}

Key words: leiomyosarcoma; spermatic cord; surgical procedures, operative

Int Braz. J Urol. 2006; 32: 66-7

\section{INTRODUCTION}

The spermatic cord is the most common site of extratesticular neoplasia. Only $30 \%$ of extratesticular neoplasms are malignant, $90 \%$ of which being sarcomas. Approximately $10 \%$ of all paratesticular sarcomas are leiomyosarcomas.

\section{CASE REPORT}

A 22-year-old man presented with a 6-month history of inguinal pain. Physical examination was unremarkable, except for a hard tender right paratesticular nodule about $0.5 \mathrm{~cm}$ in diameter. Scrotal ultrasound showed a solid nodule and normal testicles. Hemogram, liver enzymes and chest X-ray were normal.

Inguinal exploration and nodule biopsy were performed. A well-circunscribed mass was found on the upper pole of the testis. It was thought to be a benign epididymal nodule on a quick section and the tumor was enucleated and sent for paraffin section. Histology revealed interlacing bundles of spindleshaped cells with elongated and occasional pleomorphic nuclei (Figure-1). Mitoses were less than 6 per high-power fields and the tumor lacked necrosis (Figure-2). It strongly expressed muscle-specific actin, desmin and vimentin. CD68, alpha 1-antitrypsin, S100 were negative. Surgical margins were negative. The diagnosis was leiomyosarcoma.

The patient was advised to undergo radical orchiectomy with high cord ligation. However, he refused surgery and we decided for an alternative approach.

We proposed clinical, biochemical and radiological follow-up every 6 months in the first two years and annually thereafter. Routine tests were a hemogram, liver enzymes, a chest X-ray and a scrotal ultrasound. Abdominal tomography would be indicated 


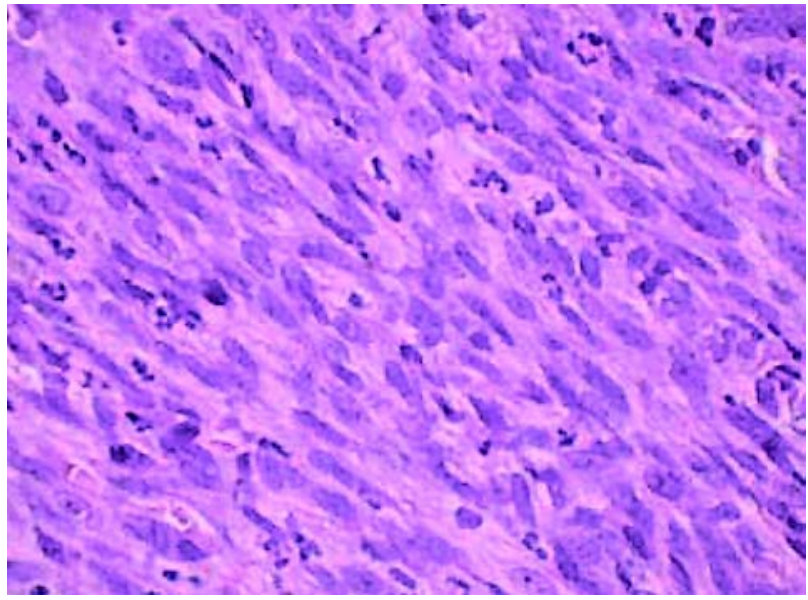

Figure 1 - Bundles of spindle-shaped cells with elongated and occasional pleomorphic nuclei (X400).

if there was an increase in liver enzymes or liver alteration in clinical examination and chest tomography for a suspected nodule on X-ray.

The patient has been followed up for thirteen years and shows no evidence of disease.

\section{COMMENTS}

Paratesticular sarcomas are rare and most of the available information derives from small series or case reports. In most cases, information about tumor grade is lacking, follow-up is short and different types of sarcomas are analyzed together.

Therefore, standard treatment for all paratesticular sarcomas consists of radical orchiectomy with high cord ligation. The role of adjuvant therapy is not clear.

Overall, 5-year disease-specific survival was $75 \%$ (1) and median interval to locoregional relapse was 36 months (2). Dissemination occurs by hematogeneous metastasis, regional lymph node spread and local extension. Our case has a long disease-free follow-up period.

Recently, a study about paratesticular leiomyosarcomas classified tumors based on the NCI system (3). Briefly, as in our case, grade I tumors lacked necrosis, had less than 6 mitosis/10 high-power fields and occasional pleomorphic nuclei.

In this series, some tumors were treated by excision. No recurrence was observed for small grade

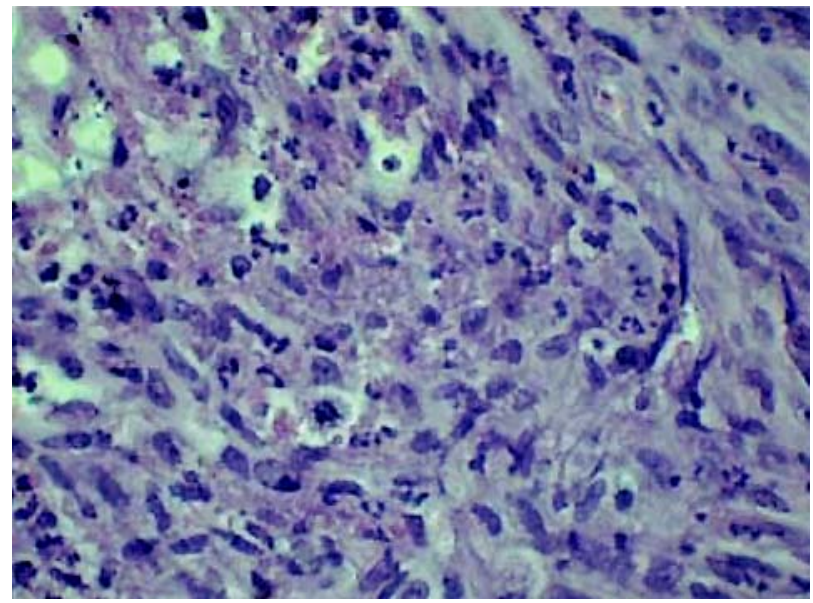

Figure 2 - Mitoses < 6/HPF and the tumor lacked necrosis (X400).

I and II tumors $(\leq 4 \mathrm{~cm})$. However, disease recurrence occurred for a large grade I tumor $(9 \mathrm{~cm})$ and a patient died of disease from a $2 \mathrm{~cm}$ grade III tumor.

Our case together with this study suggest that for small grade I and maybe for small grade II tumors, enucleation might be a good therapy if an adequate follow-up is assured. For large $(>5 \mathrm{~cm})$ or for grade III tumors, standard treatment is obligatory.

Further studies are needed and traditional management is still advisable.

\section{REFERENCES}

1. Coleman J, Brennan MF, Alektiar K, Russo P: Adult spermatic cord sarcomas: management and results. Ann Surg Oncol. 2003; 10: 669-75.

2. Fagundes MA, Zietman AL, Althausen AF, Coen JJ, Shipley WU: The management of spermatic cord sarcoma. Cancer. 1996; 77: 1873-6.

3. Fisher C, Goldblum JR, Epstein JI, Montgomery E: Leiomyosarcoma of the paratesticular region: a clinicopathologic study. Am J Surg Pathol. 2001; 25: 1143-9.

Accepted after revision: July 7, 2005

\section{Correspondence address:}

Dr. Roberto Iglesias Lopes

Rua Baronesa de Itu, 721 / 121

São Paulo, SP, 01231-001, Brazil

Fax: + 5511 3666-8266

E-mail: robertoiglesias@terra.com.br 